\title{
In vitro Antioxidant and Antidiabetic Potential of Crude Extracts from the Seed Coat and Fruit Pulp of Strychnos madagascariensis
}

\author{
Michael Osawemi Oboh ${ }^{1, *}$, Foluso Oluwagbemiga Osunsanmi ${ }^{1}$, Godfrey Elijah Zharare ${ }^{1}$, Rebamang Anthony \\ Mosa $^{2}$, Michael Chukwuka Ojo ${ }^{3}$, and Andrew Rowland Opoku ${ }^{3}$
}

\begin{abstract}
Michael Osawemi Oboh ${ }^{1, *}$, Foluso
Oluwagbemiga Osunsanmi', Godfrey Elijah Zharare', Rebamang Anthony Mosa², Michael Chukwuka Ojo ${ }^{3}$, and Andrew Rowland Opoku ${ }^{3}$

\section{${ }^{1}$ Department of Agricultural Science,} University of Zululand, Private Bag X1001, KwaDlangezwa 3886, SOUTH AFRICA. ${ }^{2}$ Department of Biochemistry, University of Pretoria, Private Bag X20, Hatfield 0028, SOUTH AFRICA.

${ }^{3}$ Department of Biochemistry and Microbiology, University of Zululand, Private Bag X1001, KwaDlangezwa 3886, SOUTH AFRICA.
\end{abstract}

\section{Correspondence}

\section{Michael Osawemi Oboh}

Department of Agricultural Science, University of Zululand, Private Bag X1001, KwaDlangezwa 3886, SOUTH AFRICA.

Phone no: +27-788-673-098;

E-mail: obohosawemi@gmail.com

History

- Submission Date: 10-05-2020;

- Review completed: 12-06-2020;

- Accepted Date: 20-06-2020

DOI : 10.5530/pj.2020.12.206

Article Available online http://www.phcogj.com/v12/i6s

\section{Copyright}

(C) 2020 Phcogj.Com. This is an openaccess article distributed under the terms of the Creative Commons Attribution 4.0 International license.

\begin{abstract}
Diabetes mellitus remains a global health issue despite the advance in orthodox medicine This study investigated the in vitro antioxidant and antidiabetic potential of crude extracts from the seed coat and pulp of Strychnos madagascariensis. The phytochemical screening was carried out using standard protocols. Different extracts were prepared from the fruit parts by maceration using methanol, $n$-hexane, ethyl acetate, and water for antioxidant and antidiabetic assays, and their percentage yield was calculated. The antioxidant potential of the extracts was determined using 2,2'-azino-bis (3-ethylbenzothiazoline-6-sulphonic acid (ABTS) and 2'2- diphenyl-1-picrylhydrazyl (DPPH). Antidiabetic activities of the extracts were investigated using $\alpha$-amylase, $\alpha$-glucosidase, and pancreatic lipase assays. Terpenoids, alkaloids and cardiac glycosides were present in both the fruit parts. However, saponin present in the fruit pulp was absent in the seed coat (testa). The percentage yields are as follows; water $>$ ethyl acetate $>$ hexane $>$ methanol (seed coat) and methanol $>$ water $>$ ethyl acetate $>$ hexane (fruit pulp), respectively. The crude extracts scavenged ABTS and DPPH radicals in different degrees. The aqueous extract of the pulp and seed coat (testa) showed significant $(P<0.05)$ higher scavenging activity against ABTS $\left(\mathrm{IC}_{50} ; 0.012\right.$ and $\left.0.006 \mathrm{mg} / \mathrm{ml}\right)$ and $\mathrm{DPPH}\left(\mathrm{IC}_{50} ; 0.06\right.$ $\mathrm{mg} / \mathrm{ml}$ and $0.064 \mathrm{mg} / \mathrm{ml}$ ) radicals than other extracts. The crude extracts inhibited $\alpha$-amylase, $\alpha$-glucosidase, and pancreatic lipase. The aqueous and methanol extracts of the fruit parts showed better amylase inhibitory activity than other extracts. The aqueous extract of the seed coat $\left(\mathrm{IC}_{50} ; 0.0785 \mathrm{mg} / \mathrm{ml}\right)$ showed the highest glucosidase inhibitory activity. In addition, methanol extract of the seed coat $\left(\mathrm{IC}_{50} ; 0.069 \mathrm{mg} / \mathrm{ml}\right)$ exhibited the highest inhibitory activity on pancreatic lipase compared to the extracts in other solvents. Hence, the aqueous and methanol crude extracts of Strychnos madagascariensis seed coat and fruit pulp could be used in the preparation of nutraceutical products for managing diabetic mellitus.
\end{abstract}

Key words: Alkaloids, Diabetes, Hyperglycaemia, Hyperlipidaemia, Phytochemicals.

\section{INTRODUCTION}

Diabetes mellitus (DM) is a collection of metabolic diseases characterized by hyperglycaemia resulting from defects in insulin secretion, insulin action, or both. ${ }^{1}$ Poorly managed hyperglycaemia often leads to long-term damage and failure of different organs, including the heart, nerves, blood vessels, kidneys and eyes. ${ }^{1}$ In the diabetic state, glucose produced by the hydrolytic action of a-amylase and $\alpha$-glucosidase is not utilized by the cells, thus leading to hyperglycaemia. In addition, diabetes enhances high levels of lipids and fats in the blood, which further intensify diabetic complication. ${ }^{2}$ The cumulative effects of these processes aggravate the production of free radicals due to compromised antioxidant defense systems. ${ }^{3}$ Despite the potency of antidiabetic drugs such as voglibose, miglitol, acarbose, their safety remains burdensome. ${ }^{4}$ The drugs are associated with unwanted side effects such as abnormal weight gain, headache, nausea, diarrhea and dizziness. ${ }^{5}$ Hence, the search for safer and cheaper alternative antidiabetic agents from plant origin.

Medicinal plants are potential sources of novel therapeutics against several chronic diseases. ${ }^{6}$ They possess naturally occurring bioactive chemicals that have medicinal properties, and hence, extensive exploration of medicinal plants in the management of diseases. The remedies derived from medicinal plants are acceptable based on its safety, accessibility, and affordability. ${ }^{7}$ Strychnos madagascariensis belongs to the Loganiaceae family. The plant is endemic to tropical and subtropical Africa including South Africa, Lesotho, Zimbabwe, and Swaziland. ${ }^{8}$ They are generally found in woodlands, rocky places, riverine fringes and coastal forest of southern Africa. ${ }^{9}$ Strychnos madagascariensis fruit is used traditionally as a food in the north coastal region of Kwazulu Natal in South Africa and the Southern part of Zimbabwe where it is claimed to curb diabetes and hypertension.

However, there is still a paucity of scientific evidence regarding the antioxidant and antidiabetic activities of this plant, despite its usage in folklore medicine. Hence, this study is the first report of the in vitro antioxidant and antidiabetic potential of Strychnos madagascariensis fruit.

Cite this article: Oboh MO, Osunsanmi FO, Zharare GE, Mosa RA, Ojo MC, Opoku AR. In vitro Antioxidant and Antidiabetic Potential of Crude Extracts from the Seed Coat and Fruit Pulp of Strychnos madagascariensis. Pharmacogn J. 2020;12(6)Suppl:1504-11. 


\section{MATERIALS AND METHODS}

\section{Chemicals}

Butylated Hydroxyl anisole (BHA), ascorbic acid (AA), $\mathrm{FeCl}_{2}$, $\mathrm{FeCl}_{3}, \mathrm{NaOH}$, potassium sodium tartrate, sodium carbonate, Tris$\mathrm{HCl}$ buffer, phosphate buffer, 3,5-dinitrosalicylic acid, potassium persulfate, 2,2'-diphenyl-1-picrylhydrazyl (DPPH), 2,2'-azino-bis(3ethylbenzothiazoline-6- sulphonic acid) (ABTS) were all purchased from Sigma-Aldrich Chemical Co. (St Louis, MO, USA). Other reagents used are 4-nitrophenyl-a-D-glucopyranoside, $p$-nitrophenyl palmitate, orlistat, methanol, hexane, ethyl acetate, and water. All chemicals used were of analytical standard.

\section{Plant collection and identification}

Strychnos madagascariensis's fruits were harvested in August 2019 at Mbazwana $\left(27.4937^{\circ} \mathrm{S}, 32.5882^{\circ}\right.$ E) KwaZulu-Natal, South Africa. The fruit was identified by Dr. N.T. Ntuli at the Department of Botany, University of Zululand. The plant's sample (voucher number VH10) was deposited at the University's herbarium.

\section{Plant extraction}

The seed coat and pulp of Strychnos madagascariensis ripe fruit were air-dried separately and pulverized using laboratory blender (Clarkson BB25EP). Different quantity of the pulverized samples was used to prepare different crude extracts by maceration using methanol, $n$-hexane, ethyl acetate and water $(200 \mathrm{ml})$ on an automatic shaker $(150$ $\mathrm{rpm} ; 25^{\circ} \mathrm{C}$ ) for $72 \mathrm{hr}$. The crude extracts were filtered using Whatman filter paper 1 . The extracts containing organic solvents were concentrated using Heidolph rotary evaporator $\left(45 \mathrm{rpm}, 40^{\circ} \mathrm{C}\right)$, whereas the aqueous extract was freeze-dried (Virtis Benchtop K). Some of the extracts were sticky, oily, while others were solid, and the percentage yield of each crude extracts was calculated using the formula below:

$\%$ yield $=\left(\mathrm{W}_{2}\right) /\left(\mathrm{W}_{1}\right) \times 100$

Where,

W1 represents the weight of the initial sample and

W2 represents the final weight of the extract.

Subsequent to the extraction process using different quantities ( $25 \mathrm{~g}$ to $60 \mathrm{~g}$ ) of the fruit parts, the weights of the different crude extracts were used to determine their percentage yield (Table 1).

\section{Phytochemicals screening}

Phytochemical screening was conducted using standard qualitative methods with slight modifications as described by Ahumuza and Kirimuhuzya, (2011) and Bibi et al., (2012). ${ }^{10-11}$ The following phytochemicals were tested for; Terpenoids, alkaloids, saponins, tannins, flavonoids and cardiac glycosides, steroids.

\section{Antioxidant studies}

\section{2,2'-azino-bis (3-ethylbenzothiazoline-6-sulphonic acid) (ABTS) scavenging activity}

The determination of ABTS scavenging activity of the extracts was carried out with the method of Re et al. ${ }^{12}$ ABTS solution $(0.003 \mathrm{~g} /$ $\mathrm{ml})$ was mixed in the ratio $1: 1(\mathrm{v} / \mathrm{v})$ with different concentrations of the crude extracts $(0-5 \mathrm{mg} / \mathrm{ml})$ respectively. The mixture was left to stand for $10 \mathrm{~min}$ at $25^{\circ} \mathrm{C}$. The absorbance was read at $734 \mathrm{~nm}$ using a spectrophotometer (Biotek plate reader). Ascorbic acid and butylated hydroxyanisole (BHA) served as positive controls. The percentage inhibition was calculated using this formula:

\% Inhibition $\left.=\left(\mathrm{A}_{0}-\mathrm{A} 1\right) / \mathrm{A}_{0}\right) \times 100$
Where,

$\mathrm{A}_{0}=$ Absorbance of control

$\mathrm{A}_{1}=$ Absorbance of sample

\section{2,2-Diphenyl-1-Picryl Hydrazyl (DPPH) scavenging activity}

The DPPH scavenging activity of the seed coat (testa) and pulp extracts was determined by the method of Brand (1995). ${ }^{13}$ The DPPH (0.02 mg/ $\mathrm{ml})$ was mixed $(1: 1 \mathrm{v} / \mathrm{v})$ with various concentration of crude extracts $(0-5 \mathrm{mg} / \mathrm{ml})$ which were dissolved in methanol. Thereafter, the mixture was made to stand for 60 minutes at $25{ }^{\circ} \mathrm{C}$, and the absorbance was read at $517 \mathrm{~nm}$ using a spectrophotometer. Ascorbic acid and Butylated Hydroxyl anisole (BHA) served as the positive controls. The percentage inhibition was calculated using this formula :

$\%$ Inhibition $\left.=\left(\mathrm{A}_{0}-\mathrm{A} 1\right) / \mathrm{A}_{0}\right) \times 100$

Where,

$\mathrm{A}_{0}=$ Absorbance of control

$\mathrm{A}_{1}=$ Absorbance of sample

\section{a-Amylase inhibitory assay}

The inhibitory effect of the seed coat (testa) and pulp crude extracts of $S$. madagascariensis on $\alpha$-amylase was determined using the method described by Adisakwattana et al (2011).$^{14}$ Starch $(200 \mu \mathrm{l})$ and plant extracts $(300 \mu \mathrm{l})$ at different concentrations $(0-5 \mathrm{mg} / \mathrm{ml})$ were made to stand for 5 minutes at $25^{\circ} \mathrm{C}$ for binding to take place. Thereafter, 200 $\mu \mathrm{l}$ of $\alpha$-amylase $(1 \mathrm{mg} / \mathrm{ml})$ was added to each mixture and was further incubated for 15 minutes at $37{ }^{\circ} \mathrm{C}$. The reaction was terminated by the addition of $250 \mu \mathrm{l}$ of 3,5-dinitrosalicylic acid ( $1 \%$ in $2 \mathrm{M} \mathrm{NaOH})$ and heated for about 10 minutes at $100{ }^{\circ} \mathrm{C}$ then cooled on ice. Thereafter, potassium Sodium Tartrate $(205 \mu \mathrm{l} ; 40 \%)$ was added and absorbance was read at $450 \mathrm{~nm}$ using a spectrophotometer. The percentage inhibition was calculated using this formula:

$\%$ Inhibition $\left.=\left(A_{0}-A 1\right) / A_{0}\right) \times 100$.

Where,

$\mathrm{A}_{0}=$ Absorbance of control

$\mathrm{A}_{1}=$ Absorbance of sample

\section{a-Glucosidase inhibitory assay}

The inhibitory effect of the crude extracts of $S$. madagascariensis on a-glucosidase was determined using the method described by Rayar and Manivannan. ${ }^{15}$ Phosphate buffer $(10 \mathrm{mM}, \mathrm{pH} 6.8 ; 50 \mu \mathrm{l}), 20 \mu \mathrm{l}$ of plant extract at different concentrations $(0-5 \mathrm{mg} / \mathrm{ml})$ and the enzyme ( $0.5 \mathrm{unit} / \mathrm{ml} ; 10 \mu \mathrm{l})$ were pre-incubated for 15 minutes at $37^{\circ} \mathrm{C}$. Then, 4-nitrophenyl-a-D-glucopyranoside) $(2.5 \mathrm{mM} ; 20 \mu \mathrm{l})$ was added to begin the reaction. The mixture was further incubated for another 20 minutes at $37^{\circ} \mathrm{C}$ before the addition of sodium carbonate $(0.1$ $\mathrm{M} ; 50 \mu \mathrm{l})$ to reduce the reaction. The absorbance was read using a spectrophotometer at $405 \mathrm{~nm}$. However, only methanol and aqueous crude extracts were investigated. Distill water served as a negative control.

\section{Pancreatic lipase inhibitory activity}

The inhibitory activity of the crude extracts on pancreatic lipase was investigated using the method described by Slanc et al. ${ }^{16}$ The mixture of Tris- $\mathrm{HCl}$ buffer $(75 \mathrm{mM}, \mathrm{pH} 8 ; 125 \mu \mathrm{l})$, various concentrations of the extract $(0-5 \mathrm{mg} / \mathrm{ml} ; 75 \mu \mathrm{l})$ and $50 \mu \mathrm{l}$ of pancreatic lipase $(10 \mathrm{mg} / \mathrm{ml}$; $50 \mu \mathrm{l}$ of) in various cells of 96 well plate was incubated for 15 minutes at $37^{\circ} \mathrm{C}$. The reaction was initiated by adding $3,3 \mathrm{mM} p$-nitrophenyl palmitate $(25 \mu \mathrm{l})$ followed by a 30 -minute incubation. Absorbance was 
measured at $405 \mathrm{~nm}$ using a spectrophotometer. Orlistat served as the positive control while methanol and water (1:1) served as the blank.

\section{Data analysis}

All treatments were in triplicate, and the values were expressed as mean \pm standard deviation. One-way Analysis of Variance (ANOVA) was used to analyze the data. The $\mathrm{IC}_{50}$ (the concentration at which $50 \%$ of the biological component was inhibited or scavenged) values were determined using the graph pad prism 6.01. The significant values of the percentage (\%) inhibition of the extracts against the measured parameters were considered as $P<0.05$.

\section{RESULTS}

\section{Percentage yield}

The hexane, ethyl acetate, and aqueous extracts from the seed coat had comparable percentage yield ranging from $25.92-30.26 \%$ while the hexane and ethyl acetate extracts from the fruit pulp had low percentage yields (Table 1).

\section{Phytochemical screening}

Both the seed coat and pulp of ripe S. madagascariensis fruits tested positive for terpenoids, alkaloids, and cardiac glycosides but negative for tannins and flavonoids. The seed coat differed from the pulp in that it tested negative for saponins while the pulp was positive for those groups of phytochemicals (Table 2).

\section{Antioxidant properties}

\section{ABTS scavenging activity}

Based on the ABTS assay, the extracts, except aqueous extracts of both samples, had concentration-dependent radical scavenging activities (Figure 1). The methanol crude extract of both samples and the fruit pulp's hexane and ethyl acetate extracts showed good free radical scavenging activity (Figure 1). The aqueous crude extracts from the seed coat $\left(\mathrm{IC}_{50}: 0.012 \mathrm{mg} / \mathrm{ml}\right)$ and fruit pulp $\left(\mathrm{IC}_{50}: 0.006 \mathrm{mg} / \mathrm{ml}\right)$ had the highest scavenging activities, while the seed coat's ethyl acetate and hexane extracts showed poor antioxidant activity (Table 3).

\section{DPPH scavenging activity}

The crude extracts from both fruit parts had concentration-dependent scavenging activity except for the seed coat's aqueous extract (Figure 2). The methanolic extract from the seed coat showed the highest antioxidant activity while the seed coat's hexane extract had the lowest activity. The seed coat's aqueous crude extract had the highest scavenging activity ( $\mathrm{IC}_{50}$ values: $0.0195 \mathrm{mg} / \mathrm{ml}$ ) against $\mathrm{DPPH}$. However, all the extracts from the fruit pulp exhibited good scavenging activity (Table 3).

\section{a-Amylase activity}

The methanol crude extracts of both fruit parts exhibited moderate a-amylase inhibitory activity (Figure 4). The aqueous, ethyl acetate and hexane extracts from both fruit parts showed weak inhibitory potential.

Table 1: Percentage yield from the seed coat and fruit extracts.

\begin{tabular}{ccc}
\hline Solvent & Seed coat (\%) & Fruit pulp (\%) \\
\hline Methanol & 9.4 & 34.25 \\
Hexane & 25.92 & 0.42 \\
Ethyl acetate & 29.96 & 1.2 \\
Water & 30.26 & 23.3 \\
\hline
\end{tabular}

Table 2: Phytochemical components of S. madagascariensis.

\begin{tabular}{ccc}
\hline Phytochemicals & Seed coat & Fruit pulp \\
\hline Terpenoids & + & + \\
Alkaloids & + & + \\
Saponins & - & + \\
Cardiac glycosides & + & + \\
Tannins & - & - \\
Flavonoids & - & - \\
\hline
\end{tabular}

Sign notations: + present, - absent

Table 3: $\mathrm{IC}_{50}$ values $(\mathrm{mg} / \mathrm{ml})$ of the extracts of S. madagascariensis on ABTS and DPPH.

\begin{tabular}{ccc}
\hline Extract & ABTS & DPPH \\
\hline SCME & $0.0665 \pm 0.0013$ & $0.0735 \pm 0.0018$ \\
SCHE & ND & ND \\
SCEAE & ND & ND \\
SCAE & $0.0120 \pm 0.0005$ & $0.0195 \pm 0.0016$ \\
FPME & $0.0650 \pm 0.0066$ & $0.0505 \pm 0.0010$ \\
FPHE & $0.0475 \pm 0.0076$ & $\mathrm{ND}$ \\
FPEAE & $0.0280 \pm 0.0209$ & $0.0925 \pm 0.00425$ \\
FPAE & $0.0060 \pm 0.0005$ & $0.0640 \pm 0.00476$ \\
AA & $0.0720 \pm 0.0343$ & $0.0210 \pm 0.00001$ \\
BHA & $0.0525 \pm 0.0107$ & $0.0665 \pm 0.0017$ \\
\hline
\end{tabular}

$\mathrm{AA}$ and $\mathrm{BHA}$ were used as the standard. Values are expressed as mean $\pm \mathrm{SD}$.

SCME- seed coat methanolic extract, SCHE- seed coat hexane extract, SCEAE- seed coat ethyl acetate extract, SCAE- seed coat aqueous extract, FPME- fruit pulp methanolic extract, FPHE- fruit pulp hexane extract, FPEAE- fruit pulp ethyl acetate, FPAE- fruit pulp aqueous extract, AA- Ascorbic acid, BHA- Butylated hydroxyanisole and ND represents not determined. Values are expressed as mean \pm SD. 
(A)

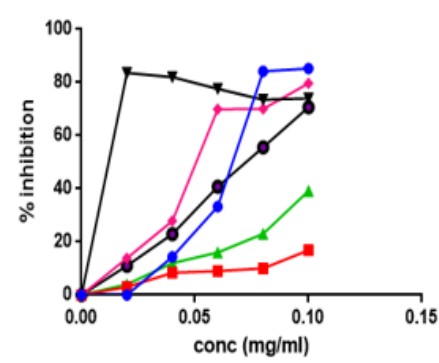

(B)

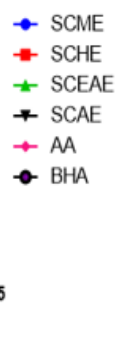

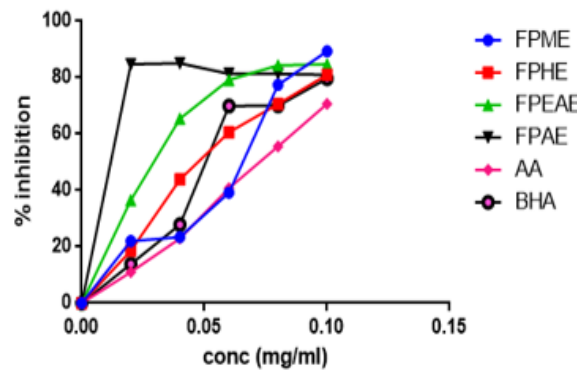

Figure 1: Scavenging activity of $S$. madagascariensis seed coat $(A)$ and fruit pulp (B) extracts against ABTS radical. SCME- seed coat methanolic extract, SCHE- seed coat hexane extract, SCEAE- seed coat ethyl acetate extract, SCAE- seed coat aqueous extract, FPME- fruit pulp methanolic extract, FPHE- fruit pulp hexane extract, FPEAE- fruit pulp ethyl acetate, FPAE- fruit pulp aqueous extract, AA- Ascorbic acid, BHA- Butylated hydroxyanisole.

(A)

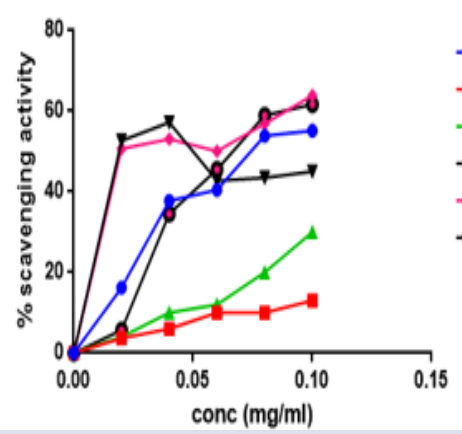

(B)

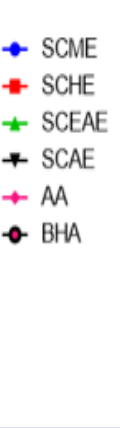

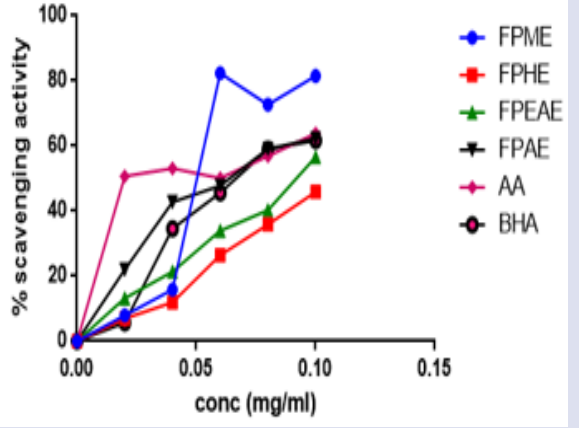

Figure 2: Scavenging activity and of S. madagascariensis seed coat (A) and fruit pulp (B) extracts against DPPH radical. Values are expressed as mean \pm SD. SCME- seed coat methanolic extract, SCHE- seed coat hexane extract, SCEAE- seed coat ethyl acetate extract, SCAE- seed coat aqueous extract, FPME- fruit pulp methanolic extract, FPHE- fruit pulp hexane extract, FPEAE- fruit pulp ethyl acetate, FPAE- fruit pulp aqueous extract, AA- Ascorbic acid, BHA- Butylated hydroxyanisole.

(A)

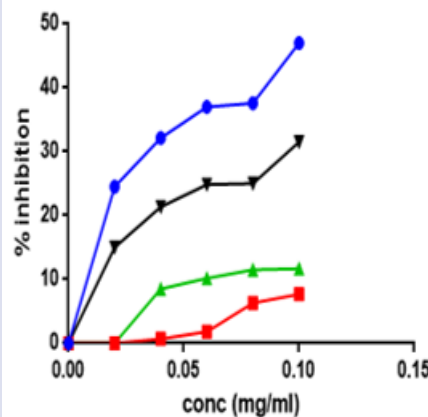

(B)

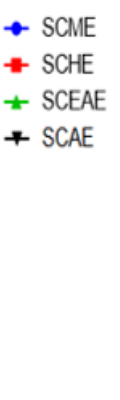

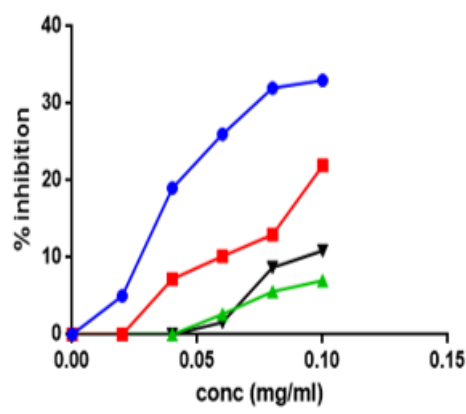

Figure 3: Inhibitory effects and $\mathrm{IC}_{50}$ values of $S$. madagascariensis seed coat $(A)$ and fruit pulp (B) extracts against a-amylase.

However, all the extracts from both fruit parts displayed concentrationdependent inhibitory activity.

\section{a-Glucosidase activity}

The methanol and aqueous extracts from both fruit parts showed concentration-dependent inhibitory activity on $\alpha$-glucosidase (Figure 4). The seed coat's aqueous extract showed higher inhibitory activity on a-glucosidase when compared to the seed coat's methanol extract. By contrast, the fruit pulp's methanol extract displayed higher inhibitory activity when compared to the fruit pulp's aqueous extract. All the extracts had concentration-dependent inhibitory activity except for the fruit pulp's methanol extract (Figure 4). The hexane and ethyl acetate extracts of both fruit parts were not tested. 


\section{Pancreatic lipase activity}

The in vitro inhibitory effect of the extracts on pancreatic lipase is shown in Figure 5. The seed coat and fruit pulp methanol extracts showed concentration-dependent inhibitory activity. However, the methanol extract from the seed coat $\left(\mathrm{IC}_{50}: 0.069 \mathrm{mg} / \mathrm{ml}\right)$ and fruit pulp $\left(\mathrm{IC}_{50}: 0.071 \mathrm{mg} / \mathrm{ml}\right)$ had the highest activity when compared to the other extracts (Table 4 ).

\section{DISCUSSION}

Many plants are known to possess naturally occurring bioactive chemicals which may have ameliorative effects on several ailments, including diabetes. ${ }^{17}$ The present study aimed to investigate the in vitro free radical scavenging and anti-diabetic activities of fruit parts (seed coat and pulp) of S. madagascariensis. This was to confirm the alleged anti-diabetic claim of ripe $S$. madagascariensis fruits by locals
(A)

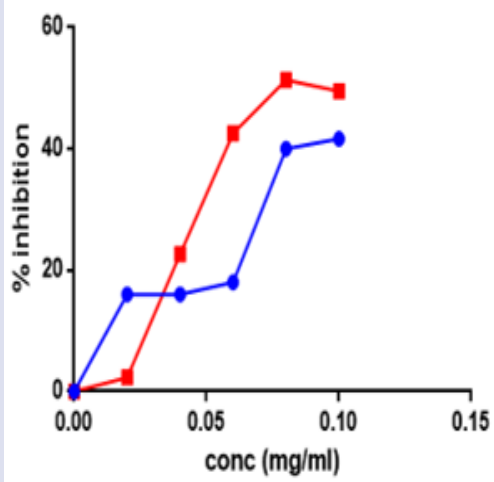

(B)

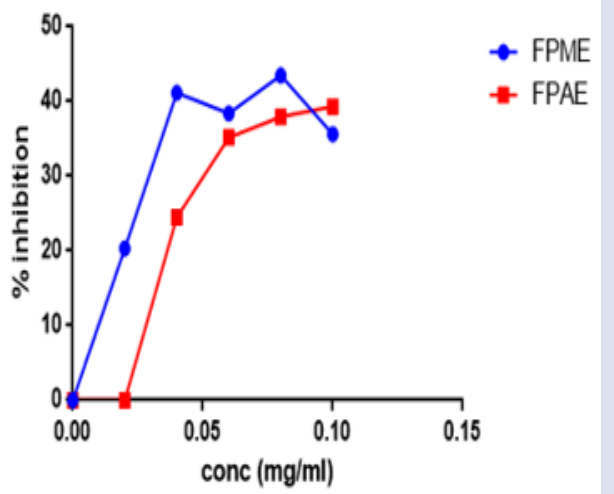

Figure 4: Inhibitory effects of S. madagascariensis seed coat (A) and fruit pulp (B) methanol and aqueous extracts respectively against a-glucosidase.
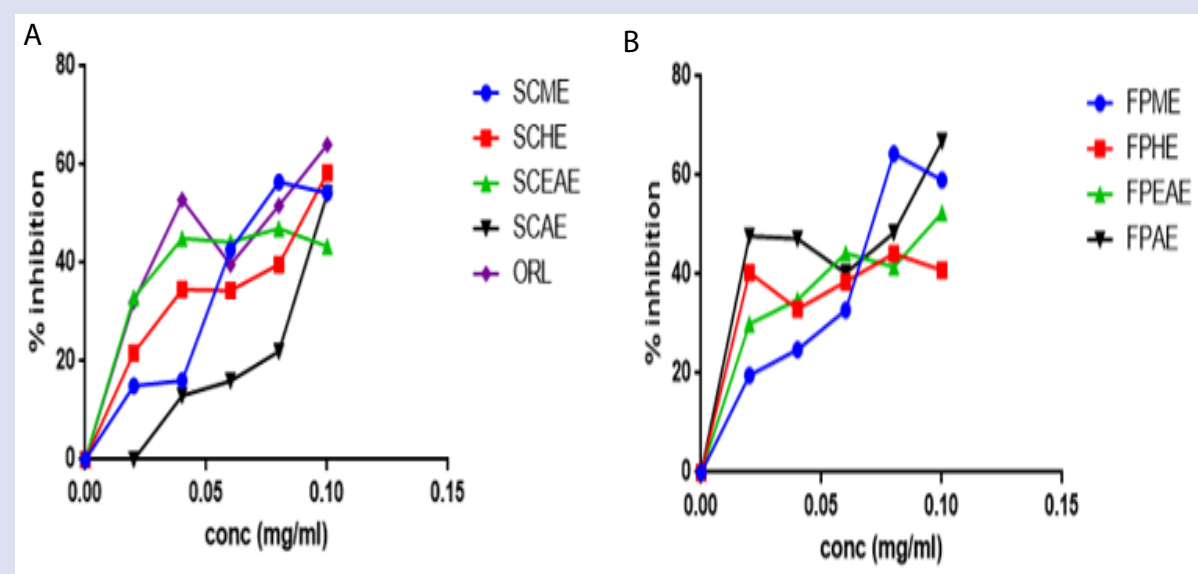

Figure 5: Inhibitory effects and $\mathrm{IC}_{50}$ values of S. madagascariensis seed coat (A) and fruit pulp (B) extracts against pancreatic lipase.

Table 4: $\mathrm{IC}_{50}$ values $(\mathrm{mg} / \mathrm{ml})$ of the extracts of $S$. madagascariensis on a-glucosidase and pancreatic lipase inhibition.

\begin{tabular}{ccc}
\hline Extract & a-glucosidase & Pancreatic lipase \\
\hline SCME & ND & $0.0690 \pm 0.0210$ \\
SCHE & ND & $0.0895 \pm 0.0021$ \\
SCEAE & ND & ND \\
SCAE & $0.0785 \pm 0.02100$ & $0.0975 \pm 0.0007$ \\
FPME & ND & $0.0705 \pm 0.0277$ \\
FPHE & ND & ND \\
FPEAE & ND & $0.0950 \pm 0.0293$ \\
FPAE & ND & $0.0805 \pm 0.3360$ \\
ORL & ND & $0.0550 \pm 0.0070$
\end{tabular}

SCME- seed coat methanolic extract, SCHE- seed coat hexane extract, SCEAE- seed coat ethyl acetate extract, SCAE- seed coat aqueous extract, FPME- fruit pulp methanolic extract, FPHEfruit pulp hexane extract, FPEAE- fruit pulp ethyl acetate extract, FPAE- fruit pulp aqueous extract, ORL- Orlistat and ND represents not determined. Values are expressed as mean \pm SD. 
in the northern coastal region of KwaZulu Natal. The medicinal efficacy of plant extracts is determined by the method of extraction ${ }^{18}$ and the solubility of the concerned phytochemicals in the solvent used during the extraction. The high extraction yield of methanol and water suggest that the compounds in the seed coat (testa) and fruit pulp are highly soluble in these solvents since the extractability of a solvent is generally due to the solubility of the compounds in the solvent used.$^{19}$ Phytochemical screening of the seed coat and fruit pulp indicated that alkaloids, cardiac glycosides, and terpenoids were present in the seed coat and fruit pulp of S. madagascariensis (Table 2), which might impart antioxidant and anti-diabetic activities to these fruit parts. Indeed, in support of this, the aqueous extracts of both fruit parts, the seed coat's methanol, and the fruit pulp's hexane and ethyl acetate extracts showed high antioxidant activities when compared to other extracts from the fruit parts. Apart from the methanol and aqueous extracts which showed anti-diabetic activities by reducing the activities of carbohydrate digestive enzymes (Figure 3 and 4), the seed coat's hexane and fruit pulp's ethyl acetate extracts showed lipase inhibitory activity (Figure 5) suggest that these extracts could prevent hyperlipidemia which is one of the contributory factors to diabetes mellitus. ${ }^{20}$ This shows the potential of the seed testa and pulp of the ripe fruit of $S$. madagascariensis to reduce post-prandial free fatty acid and subsequent control on diabetes mellitus which is linked to oxidative stress due to the damaging effects of hyperlipidemia. ${ }^{21}$ The inhibition of these enzymes delays the release of glucose, causing a decrease in blood sugar levels. ${ }^{22}$ Several relevant phytochemicals such as alkaloids, terpenoid, cardiac glycosides, saponins, steroids have shown amelioration of hyperglycemia through the inhibition of $\alpha$-amylase and $\alpha$-glucosidase. ${ }^{23-24}$ Hence, the high antioxidant and antidiabetic activities of the fruit parts' extracts observed for $S$. madagascariensis in this study may contribute to the inhibition of the manifestation of diabetes-related symptoms.

\section{CONCLUSION}

This study highlights the free radical scavenging and enzyme inhibitory potential of extracts from the seed coat and fruit pulp of $S$. madagascariensis and offers scientific backing to its folklore usage in the management of diabetes mellitus. The extracts displayed diverse anti-diabetic activities that could be linked to the phytochemicals such as alkaloids, terpenoids, cardiac glycosides, present in the extracts. The aqueous and methanol extracts of the fruit parts showed higher in vitro antioxidant and antidiabetic activity compared to other extracts by efficiently scavenging free radicals and inhibiting carbohydrates ( $\alpha$-amylase and $\alpha$-glucosidase) and lipids (pancreatic lipase) digestive enzymes making the ripe fruit of importance in the management of diabetes mellitus. For further studies, detailed phytochemical constituents of the fruit parts (seed coat and pulp) need to ascertain using Liquid chromatography Mass Spectroscopy (LC-MS). Likewise, in vivo antidiabetic potential of the crude extracts needs to be carried out.

\section{FUNDING}

The author appreciates the financial supports of the Research Office, University of Zululand, South Africa.

\section{CONFLICTS OF INTEREST}

None declared.

\section{REFERENCES}

1. American Diabetes Association. Diagnosis and classification of diabetes mellitus. Diabetes care. 2010:33:S62-9.
2. Spencer MW, Mühlfeld AS, Segerer S, Hudkins KL, Kirk E, LeBoeuf RC, et al. Hyperglycaemia and hyperlipidaemia act synergistically to induce renal disease in LDL receptor-deficient BALB mice. American journal of nephrology. 2004;24(1):20-31.

3. Maritim AC, Sanders A, Watkins JB. Diabetes, oxidative stress, and antioxidants: a review. Journal of biochemical and molecular toxicology. 2003;17:24-38.

4. Elekofehinti OO. Saponins: Anti-diabetic principles from medicinal plants-A review. Pathophysiology. 2015;22:95-103.

5. Inzucchi SE, Bergenstal RM, Buse JB, Diaman M, Ferrannini E, Nauck M et al. Management of hyperglycemia in type 2 diabetes: a patient-centered approach: position statement of the American Diabetes Association (ADA) and the European Association for the Study of Diabetes (EASD). Diabetes Spectrum. 2012;25:154-71.

6. Iwu MW, Duncan AR, Okunji CO. New antimicrobials of plant origin Perspectives on new crops and new uses. ASHS Press, Alexandria, VA 1999:457-62.

7. Gaikwad BS, Krishna MG, Sandhya RM. Phytochemicals for diabetes management. Pharmaceutical Crops. 2014;5:1.

8. Adebowale A. Biosystematic studies in Southern African species of Strychnos $L$ (Loganiaceae). Doctoral thesis, University of KwaZulu-Natal, Durban, South Africa, 2015

9. Ngadze RT, Linnemann AR, Nyanga LK, Fogliano V, Verkerk R. Local processing and nutritional compositio of indigenous fruits: The case of monkey orange (Strychns spp) from Southern Africa. Food Reviews International. 2017;33(2):123-42

10. Ahumuza T, Kirimuhuzya C. Qualitative (phytochemical) analysis and antifungal activity of Pentas decora (De wild), a plant used traditionally to treat skin fungal infections in Western Uganda. Research in Pharmaceutical Biotechnology 2011;3:75-84.

11. BibiY, Nisa S, Zia M, Waheed A, Ahmed S, Chaudhary MF. In vitro cytotoxic activity of Aesculus indica against breast adenocarcinoma cell line (MCF-7) and phytochemical analysis. Pakistan Journal of Pharmaceutical Sciences. 2012;25:183-7.

12. Re R, Pellegrini N, Proteggente A, Pannala A, Yang M, Rice-Evans C. Antioxidant activity applying an improved ABTS radical cation decolorization assay. Free radical biology and medicine. 1999;26:1231-37.

13. Brand-Williams W, Cuvelier ME, Berset CL. Use of a free radical method to evaluate antioxidant activity. LWT-Food Science and Technology. 1995;28:25-30.

14. Adisakwattana S, Lerdsuwankij O, Poputtachai U, Minipun A, Suparpprom C. Inhibitory activity of cinnamon bark species and their combination effect with acarbose against intestinal $\alpha$-glucosidase and pancreatic $\alpha$-amylase. Plant Foods for Human Nutrition. 2011;66:143-8.

15. Rayar A, Manivannan R. In-vitro alpha-amylase and alpha-glucosidase inhibition activity of umbelliferone and beta-ionone isolated from Coriandrum sativum Linn. World Journal of Pharmacy and Pharmaceutical Sciences. 2016;5:1280-9.

16. Slanc P, Doljak B, Kreft S, Lunder M, Janeš D, Štrukelj B. Screening of selected food and medicinal plant extracts for pancreatic lipase inhibition. Phytotherapy Research: An International Journal Devoted to Pharmacological and Toxicological Evaluation of Natural Product Derivatives. 2009;23:874-7.

17. Gaikwad BS, Krishna MG, Sandhya RM. Phytochemicals for diabetes management. Pharmaceutical Crops. 2014,5.

18. Odey MO, Iwara IA, Udiba UU, Johnson JT, Inekwe UV, Asenye ME, et al. Preparation of plant extracts from indigenous medicinal plants. Int J Sci-Tech. 2012;688-92.

19. Dhanani T, Shah, S, Gajbhiye NA, Kumar S. Effect of extraction methods on yield, phytochemical constituents and antioxidant activity of Withania somnifera. Arabian Journal of Chemistry. 2017;10:S1193-9.

20. Kopelman PG. Obesity as a medical problem. Nature. 2000;404(6778):635-43.

21. Barbosa A, Silveira GD, de Menezes I, Neto J, Bitencurt J, Estavam CD, et al. Antidiabetic effect of the Chrysobalanus icaco L. aqueous extract in rats. J. Med. Food. 2013;16:538-43.

22. Rayar A, Manivannan R. In-vitro alpha-amylase and alpha-glucosidase inhibition activity of umbelliferone and beta-ionone isolated from Coriandrum sativum Linn. World Journal of Pharmacy and Pharmaceutical Sciences. 2016;5:1280-9.

23. Jung $M$, Park M, Lee HC, Kang YH, Kang ES, Kim SK. Antidiabetic agents from medicinal plants. Current medicinal chemistry. 2006;13:1203-18.

24. Ponnusamy S, Ravindran R, Zinjarde S, Bhargava S, Ravi Kumar A. Evaluation of traditional Indian antidiabetic medicinal plants for human pancreatic amylase inhibitory effect in vitro. Evidence-Based Complementary and Alternative Medicine. 2011. 


\section{GRAPHICAL ABSTRACT}

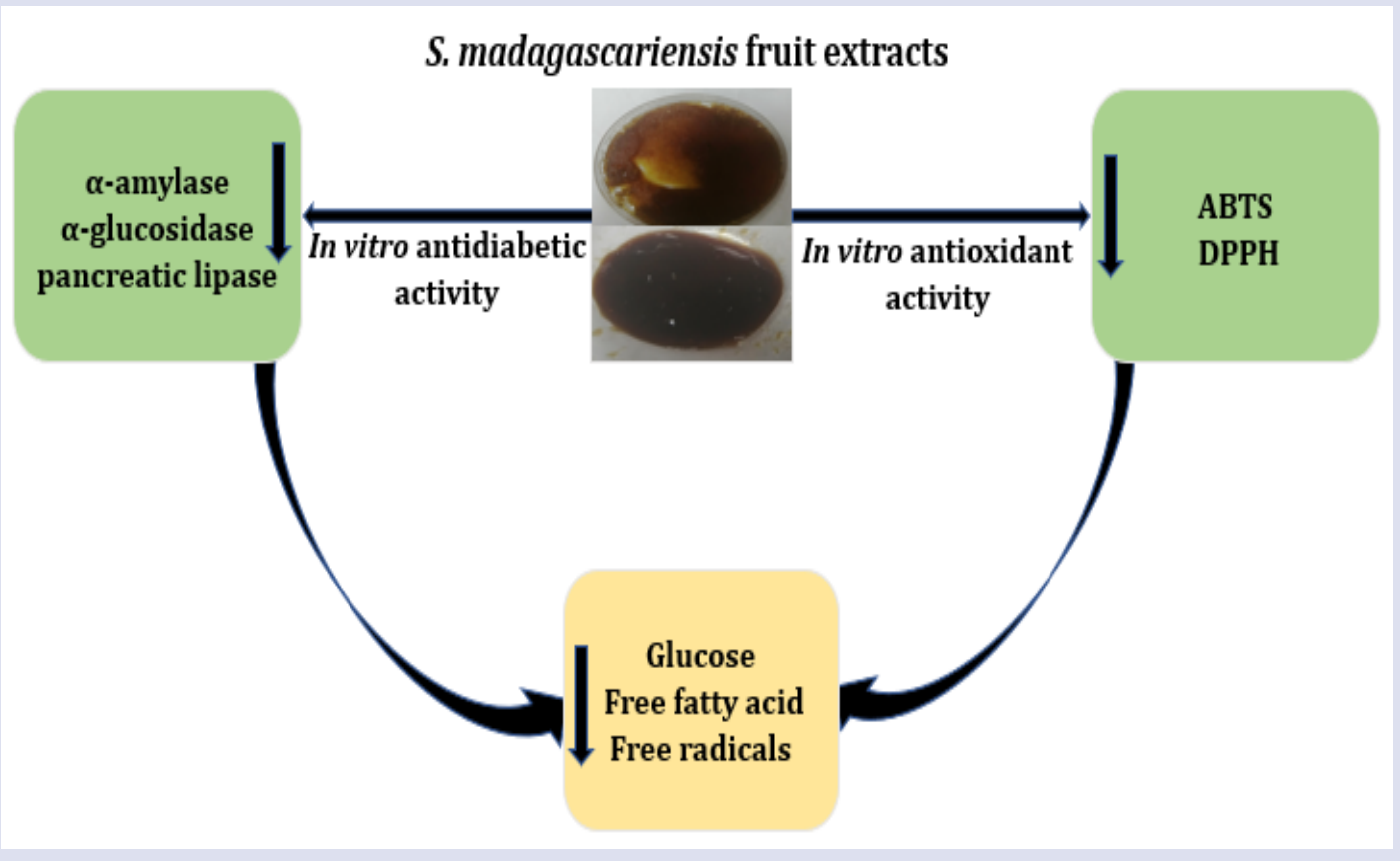

\section{ABOUT AUTHORS}

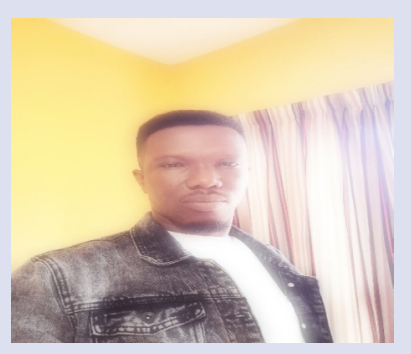

Mr Michael Osawemi Oboh is the first and corresponding author of this article. He completed his BSc (Honours) in Human Physiology from Ambrose Alli University, Nigeria in 2010. In 2017, he obtained BSc degree (honours) in Biochemistry from the University of Zululand, South Africa. He further completed his MSc in 2019 from the same University.

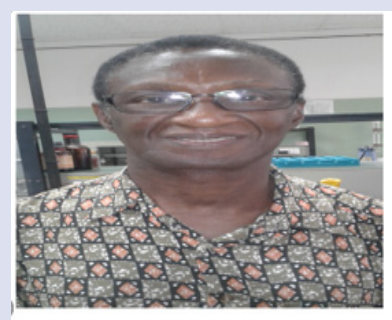

Prof. Andy Rowland Opoku obtained his PhD in 1977 from the University of Manchester, United Kingdom. He had academic positions in various universities across Africa. Currently, he is working as professor emeritus in the University of Zululand, South Africa with lots of publications.

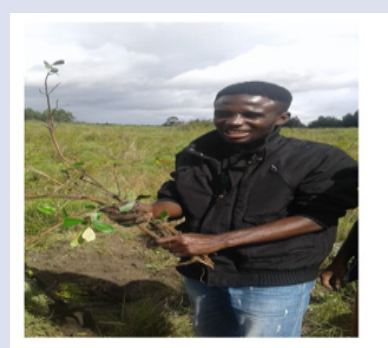

Mr Michael Chukwuka Ojo is at present a PhD candidate in the University of Zululand. He just recently bagged his MSc in Biochemistry from the University. He bagged his BSc honours degree in Biochemistry in the year 2010 from the University of Benin, Nigeria. An honours award in Biochemistry was added to him in Biochemistry from the University of Zululand, South Africa in 2017. 

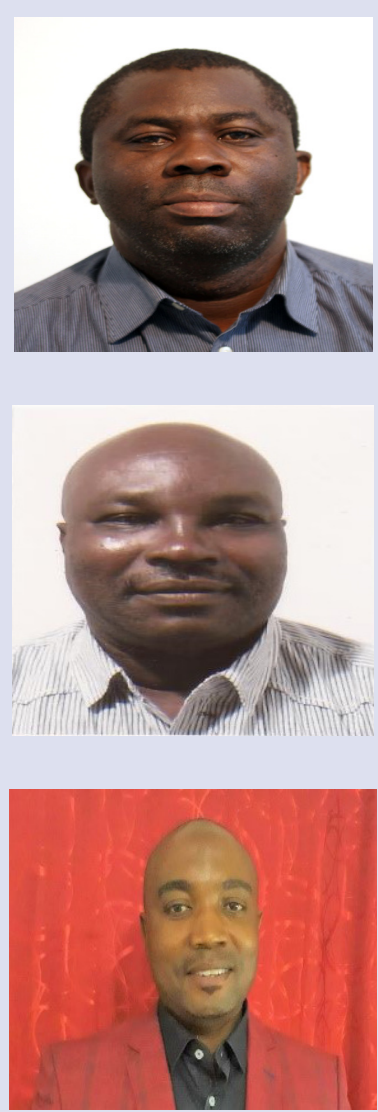

Dr. Foluso 0 Osunsanmi is currently a researcher at the Department of Agricultural Science, University of Zululand, South Africa. He is a biochemist with over nineteen-years' work experience in both academic and industrial sectors. He had notable publications reputable journals and had present both in local and international conferences, He regularly performs peer review for twenty-two different journals. He is an Academic Editor of many internal journals. He is also member of South Africa Council for Natural Scientific Professional, South Africa Association of Clinical Biochemistry and National Association of Safety Professional.

Prof. Godfrey Elijah Zharare obtained his PhD qualification in Agronomy/crop nutrition from the University of Queensland in Australia. He is currently the head of Department of Agriculture at the University of Zululand. He is a C3 level rated NRF researcher in South Africa. He is currently working on domestication of indigenous plants in KwaZulu -Natal, with special emphasis on Strychnos species.

Dr Rebamang A Mosa holds a PhD in Biochemistry (2014) from the University of Zululand, RSA. $\mathrm{He}$ is currently a senior lecturer and researcher in the Department of Biochemistry, Genetics and Microbiology, University of Pretoria. Dr Mosa has made substantial contribution, through research publications, to the field of medicinal plants and natural products research. He has so far authored and co-authored more than 30 articles in peer-reviewed reputable journals. He has also authored and co-authored 14 poster and oral presentations at both local and international conferences. He currently serves as an active reviewer of a number of internationally reputable journals.

Cite this article: Oboh MO, Osunsanmi FO, Zharare GE, Mosa RA, Ojo MC, Opoku AR. In vitroAntioxidant and Antidiabetic Potential of Crude Extracts from the Seed Coat and Fruit Pulp of Strychnos madagascariensis. Pharmacogn J. 2020;12(6)Suppl:1504-11. 